rất quan trong và cũng là công việc khó khăn nhất ở những vùng dân cư có mật độ di biến động lớn, đặc biệt là những thành phố đô thị lớn và khu công nghiệp.

\section{KẾT LUÂ̂N}

Các vắc xin đống gói càng nhiều liều tỷ lệ hao phí càng cao, có mối tương quan với dân số, số đối tượng, số buổi tiêm chủng, địa hình. Vắc xin đơn liều DPT-VGB-Hib ít phụ thuộc vào những yếu tố trên. Có thể giảm liều đống gói vắc xin VAT và DPT từ 20 liêu/lọ thàng 10 liều/lọ. Cần đầu tư và duy trì hệ thống bảo quản, vận chuyển dây chuyền lạnh chuyên dụng từ tuyến trung ương đến địa phương. Cán bộ quản lý tiêm chủng cần quản lý tốt đối tượng của địa phương, nắm rõ dân số, số đối tượng, đặc tính dân số, kỹ năng tổ chức buổi tiêm chủng. Kết quả nghiên cứu là cơ sở đưa ra các khuyến nghị giúp tỉnh/thành triển khai công tác quản lý vắc xin tiêm chủng mở rộng tốt hơn và tìm giải pháp giảm hao phí vắc xin.

\section{TÀI LIẸU THAM KHẢO}

1. Organization WH. Monitoring vaccine wastage at country level: guidelines for programme managers. Geneva: World Health Organization; 2005.
2. Trịnh Trung Trực*. Võ Ngọc Quang TQT, Nguyễn Thi Thu Trang, Hoàng Anh Thắng, Phan Thị Quỳnh Trâm, Hồ Vình Thắng. Thực trạng hệ số sử dụng vắc xin trong Tiêm chủng mở rộng tại 20 tỉnh/thành KVPN năm 2018. Tạp chí Y Học Dự Phòng. 2019:48.

3. Minh VPTCMRKVPN-VPTpHC. Báo cáo hê số sử dụng vắc xin Khu vực Phía Nam từ năm 2015 đến nằm 2019. Viên Pasteur Thành Phố Hồ Chí Minh. 2019.

4. Báo cáo Tiềm chủng mở rộng Khu vức Phía Nam năm 2015. Viện Pasteưr Thành Phố Hồ Chí Minh. 2015.

5. Viện Vệ sinh dịch tễ Trung ương (2017) Quyết định số $11 / \mathrm{Q} Đ-V S D T T U$ V Vê việc phê duyệt định múcc sử dụng, dự trử vắc xin vật tư Tiêm chủng trong dự án Tiêm chủng mở rộng. Thư Viện Pháp Luât.

6. Viện Vệ sinh dịch tễ Trung ương (2019) Quyết định 1193/Q̄Đ-VSDTTU' "điều chỉnh mức sứ dụng, dự trữ vắc xin và vật tư tiêm chủng trong Dự an Tiêm chủng mở rộng". Bộ Y Tế. 2019.

7. Mohammed SA, Workneh BD. Practical experience of vaccinators and vaccine handlers in vaccine cold chain management: A phenomenological study. Ethiopian Journal of Health Development. 2021;35(1).

8. Kure BC, Olugbenga OT, Mamzhil R, Crown S, Paul BA, Sabuwa BH, et al. Vaccine Management in North Central Nigeria: A Review of the Impact of Optimized Integrated Routine Immunization System, Kaduna State, Nigeria. 2019.

\title{
TỶ LÊ TIÊM CHỦNG ĐÂYY ĐỦ, ĐÚNG LICCH CỦA TRẺ EM THEO CHƯO'NG TRÌNH TIÊM CHỦNG MỞ RộNG VÀ CÁC YẾU TỐ LIÊN QUAN TẠI THÀNH PHỐ PHAN THIẾT, TỈNH BÌNH THUÂ̂N
}

\author{
Vũ Thị Thúy*,Võ Văn Hạn*, Nguyễn Thị Tho*,
} Hồ Hoàng Vũ $\tilde{u}^{* *}$,Trần Thiện Thuần**

\section{TÓM TẮT}

Mục tiêu: Xác định tỷ lệ trẻ dưới 1 tuổi được tiêm chủng đầy đủ, đúng lịch 8 loại vắc xin và các yếu tố liên quan tại thành phố Phan Thiết, tỉnh Bình Thuận trong năm 2020. Phương pháp: Thiết kế nghiên cứu cắt ngang mô tả trên 370 trẻ emtrong độ tuổi $9-21$ tháng tuổi đến $31 / 12 / 2020$ đang sống tại thành phố Phan Thiết, tỉnh Bình Thuận đến thời điểm nghiên cứu và bà me (người trực tiếp chăm sóc trẻ) trên 18 tuổi đang sống taii thành phố Phan Thiết, tỉnh Bình Thuận đến thời điểm nghiên cứu thông qua phương pháp chọn mâu PPS, chọn ngâu nhiên 30 cụm (đơn vị cụm

\footnotetext{
*Trung tâm Kiểm soát bệnh tật Bình Thuận

**Đai hoc Y Dước TP Hồ Chí Minh

Chịu trách nhiệm chính: Vũ Thị Thúy

Email: thuyvut4g@gmail.com

Ngày nhận bài: 29/10/2021

Ngày phản biên khoa họ: 25/11/2021

Ngày duyệt bài: 17/12/2021
}

là 121 thôn/khu phố của 17 xã/phường của thành phố Phan Thiết). Kết quả: Tỷ lệ tiêm chủng đầy đủ, tại thành phố Phan Thiết, tỉnh Bình Thuân trong năm 2020 là $78.11 \%$, tiêm chủng đúng lịch là $1.98 \%$. Các yếu tố liên quan đế tỷ lệ tiêm chủng đầy đủ 8 loại vắc xin cho trẻ dưới 1 tuổi được nhận định bao gồm: Trình độ học vấn; hết cấp 2 PR:1.23, KTC 95\%(1.01-1.50) $(p=0.01)$ hết cấp3PR: 1.27 KTC $95 \%(1.05-1.54)$ $\mathrm{p}=0.04$, trên cấp 3 PR: 1.23 KTC 95\%(1.01-1.49) $p=0.01$. Nơi ở, vung ven thành thị PR: $1.23 \mathrm{KTC} 95 \%$ (1.11-1.36) $p=0.00$. Sổ tiêm chủng PR 4.81 KTC $95 \%$ (1.36-17.06) $\mathrm{p}=0.00$; Biết nđ̛i, tiêm giờ tiêm PR 2.38 KTC 95\% (1.07-5.32) $\mathrm{p}=0.00$; trẻ bi hoãn tiêm PR 0.84 KTC $95 \%(0.72-0.98) p=0.01$, Không tin vào tiêm chủng PR 0.83 KTC 95\% (0.7-0.98) $p=0.01$; nghe đồn không đúng về tiêm chủng PR 0.76 KTC $95 \%$ (0.60$0.97) p=0.00$; kết vắc xin $P R=0.81 K T C 95 \%(0.67-$ 0.97) $\mathrm{p}=0.01$; mẹ bận PR 0.77 KTC $95 \%$ (0.63-0.95) $p=0.00$, trẻ bệnh PR 0.85 KTC $(0.77-0.95) p=0.00$, lựa chọn nơi tiêm PR 2.23 KTC 95\% $(1.86-2.66) \mathrm{p}=0.00$. Kểt luận: Tỷ lệ tiêm chủng đầy đủ, 8 loại vắc xin truong chương trình tiêm chủng mở rộng là $78.11 \%$, 
tiêm chủng đúng lịch là $1.98 \%$. Các yếu tố ảnh hưởng đến tỷ lệ tiêm chủng đây đủ 8 loại vắc xin cho trẻ dưới 1 tuổi bao gồm: trình độ học vấn, nơi ở, sổ tiêm chủng,lựa chọn nơi tiêm, các yếu tố về thiếu thông tin tiêm chủng, trở ngại tiêm chủng, thiếu vận động về tiêm chủng.

Tư khóa: Tỷ lệ tiêm chủng đây đủ, đúng lịch, Phan thiết, Bình Thuận.

\section{SUMMARY}

FULL IMMUNIZATION COVERAGE AND ON SCHEDULE OF VACCINES IN CHILDREN IN THE EXPANDED PROGRAM ON IMMUINZATION AT PHAN THIET DISTRICTIN BINH THUAN

Objectives: To determine the rate and associated factors of full and on schedule immunization with 8 types of vaccine on under 1 year-old children at Phan Thiet city, Binh Thuan province in 2020. Methods: A cross-sectional study. Information on vaccination status was collected from immunization report from 370 children aged 9-21 months. A total of 370 mothers/caretakers over 18 years old were interviewed from December 31, 2020. Results: $78.11 \%$ of children were fully immunized and $1.98 \%$ were immunized on schedule. Some association factors with full immunization of children under 1 year were place of residence in rural compared to urban areas (PR: 1.23, 95\% CI: 1.11; 1.36, p<0.001), presence of vaccination document $(P R=4.81,95 \%$ IC: $1.36 ; 17.06, p<0.001)$, the mother knew the schedule and place of immunization (PR 2.38, 95\% IC: $1.07 ; 5.32, \mathrm{p}<0.001)$, sick children delays and delayed well children immuzination were statistically significantly associated with the full immunization $(P R=0.84,95 \%$ IC: $0.72 ; 0.98, p=0.01$ and $P R \quad 0.85$, 95\% IC: $0.77 ; 0.95, p<0.001)$, negative attitude of the mothers such as no beliefs in immunization (PR $0.83,95 \%$ IC: $0.7 ; 0.98, p=0.01$ ) or misconceptions on immunization (PR 0.76, 95\% IC: $0.60 ; 0.97$, $\mathrm{p}<0.001)$, shortage of vaccines supplies ( $P R=0.81$, 95\% IC: $0.67 ; 0.97, p=0.01$ ), the lack of time (PR $0.77,95 \% \mathrm{CI}: 0.63 ; 0.95, \mathrm{p}<0.001)$ and mother's education level. The full of vaccination coverage were $1.27(\mathrm{PR}=1.27,95 \% \mathrm{CI}: 1.05 ; 1.54, \mathrm{p}=0.04)$ and $1.23(\mathrm{PR}=1.23,95 \% \mathrm{CI}: 1.01 ; 1.50, \mathrm{p}=0.01)$ or $(\mathrm{PR}$ $=1.23,95 \% \mathrm{CI}: 1.01,1.49 ; \mathrm{p}=0.01)$ times higher in children of mothers with primary and secondary or higher high school ducation respectively than children of mothers with no education. Conclusion: Full immunization coverage in this study was lower than the national target. Improving maternal education is important for increasing vaccination coverage. On the other hand, it's necessary to communicate knowlegde about expanded programme of immunization with 8 types vaccines for mother/carertakes have children under 12 months. Besides, aregular supply of vaccines will reduce the missed opportunities, thus maintaining high vaccination coverage in children.

Keywords; Full immunization coverage; on schedule vaccination; vaccine, Phan Thiet, Binh Thuan.

\section{I. ĐẶT VẤN ĐỀ}

Theo Tổ chức $Y$ tế Thế giới, tiêm chủng vắc xin là một trong những công cụ mạnh mẽ nhất trong lịch sử y tế công cộng, giúp phòng chống các bệnh truyền nhiễm nguy hiểm gây tử vong hàng đầu ở trẻ em. WHO ước tính tiêm chủng đã cứu sống gần 3 triệu người mỗi năm và là một trong những khoản đầu tư y tế hiệu quả nhất[9]. Những năm gần đây, tỷ lệ tiêm chủng đầy đủ trên toàn thế giới chỉ duy trì ở mức dưới $85 \%$. Việc lưỡng lự khi tiêm vắc xin đã trở thành 1 trong 10 nguy cơ về y tế công cộng trên toàn thế giới, làm đảo ngược tiến độ phòng chống các bệnh có thể phòng ngừa được bằng vắc xin.

Tại Việt Nam, côngtác tiêm chủng còn gặp nhiêu khó khăn, tạolỗ hổng trong công tác tiêm chủng, phòng chống dịch bệnh ở trẻ em[3], [4]. Đặc biệt, tỷ lệ tiêm chủng đầy đủ, đúng lịch tại thành phố Phan Thiết trong những năm gần đây thấp hơn các địa phương khác trên địa bàn tỉnh [1]. Vì vậy chúng tôi chọn thực hiện đề tài "Tỷ lệ tiêm chủng đầy đủ, đúng lịch của trẻ em dưới một tuổitheo chương trình tiêm chủng mở rộng và các yếu tố liên quantại thành phố Phan Thiết, tỉnh Bình Thuận năm 2020" với hai mục tiêu:

- Xác định tỷ lệ trẻ dưới 1 tuổi được tiêm chủng đầy đủ, đúng lịch 8 loại vắc xin cho tại thành phố Phan Thiết, tỉnh Bình Thuận trong năm 2020.

- Xác định mối liên quan giữa tỷ lệ tiêm chủng đầy đủ 8 loại vắc xin cho trẻ dưới 1 tuổi với với các yêu tố liên quan tại thành phố Phan Thiết, tỉnh Binh Thuận trong năm 2020.

\section{II. ĐỐI TƯỢNG VÀ PHƯƠNG PHÁP NGHIÊN CỨU \\ 2.1. Thiết kế nghiên cứu: Nghiên cứu mô} tả cắt ngang

2.2. Địa điểm, thời gian: Từ tháng $02 / 2021$ -10/2021 tại 121 thôn/khu phố của 17 phường/xã tại Thành phố Phan Thiết, tỉnh Bình Thuận.

2.3. Cỡ mẫu. Đối tượng nghiên cứu là 370 trẻ em và bà mẹ Trẻ em trong độ tuổi $9-21$ tháng tuổi đến 31/12/2020; Bà mẹ (người trực tiếp chăm sóc trẻ) trên 18 tuổi đang sống tại thành phố Phan Thiết, tỉnh Bình Thuận đến thời điểm nghiên cứu.

Tiêu chí chọn vào:

- Trẻ em trong độ tuổi 9 - 21 tháng tuổi tính đến ngày 31 tháng 12 năm 2020.

- Các trẻ trên hiện đang sống tại thành phố Phan Thiết từ 3 tháng trở lên

- Trẻ có mẹ hoăc người trực tiếp chăm sóc trẻ.

- Mẹ hoăc người trực tiếp chăm sóc trẻ đồng ý tham gia nghiên cứu.

Tiêu chí loại ra: 
- Đối tượng bị hạn chế khả năng nghe, đọc và trả lời phỏng vấn (ngoại trừ trẻ).

- Đối tượng vắng nhà sau 3 lần đến điều tra.

- Đối tượng bỏ ngang cuộc phỏng vấn, học tham gia phỏng vấn không quá $50 \%$ số câu hỏi

2.4. Xử lý số liệu: Phỏng vấn theo bộ câu hỏi tự điền. Kỹ thuật: phỏng vấn bán cấu trúc, sử dụng thêm phướng pháp liệt kê tự do. Kết quả thu thập được nhập liệu bằng phần mềm Epidata và phân tích số liệu bằng Stata 14.2.

2.5. Vấn đề $Y$ đức. Đề tài đã được sự chấp thuận của Hội đồng Đạo đức trong nghiên cứu y sinh học theo quyết định số 951/HĐĐĐ-Ð ngày 18 tháng 12 năm 2020 trường Đại học $\mathrm{Y}$ Dược thành phố Hồ Chí Minh Đồng thời nghiên cứu này được sự chấp thuận của Sở $Y$ tế tỉnh Bình Thuận trước khi thực hiện.

\section{KẾT QUẢ NGHIÊN CỨU}

Qua quá trình điều tra, thu thập số liệu trên 370 bà mẹ/người chăm sóc trẻ về tiêm chủng cho trẻ dưới 1 tuổi trong chương trình tiêm chủng mở rộng tại thành phố Phan Thiết, tỉnh Bình Thuận năm 2020, thu được những kết quả sau:

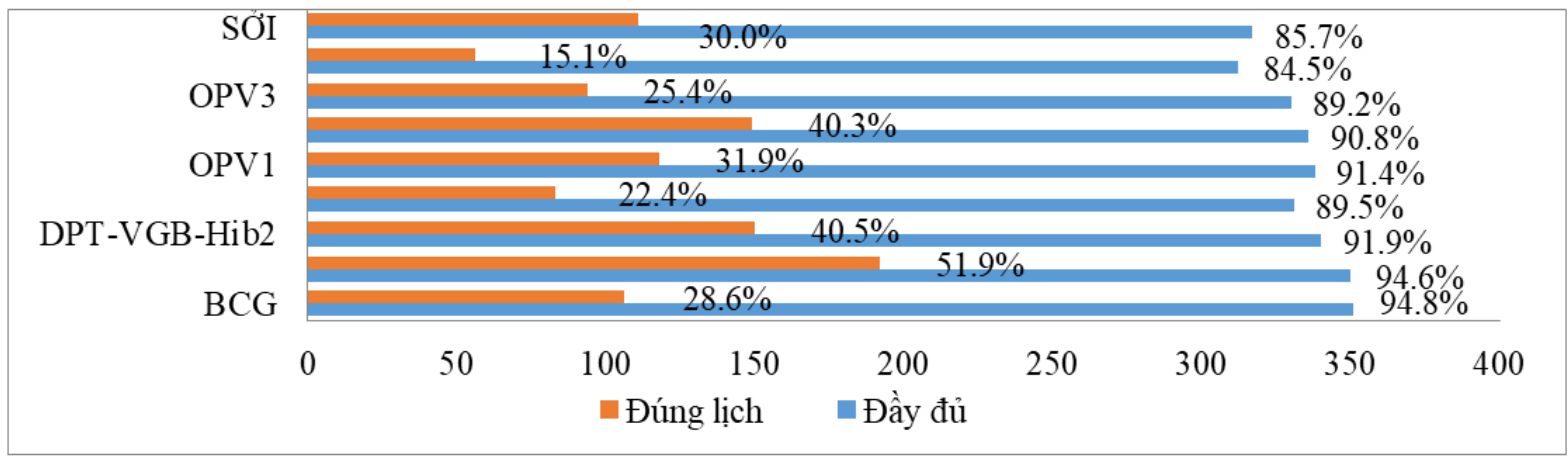

Biểu đồ 3.1. Tiêm chủng đầy đủ, đúng lịch từng loại vắc xin ( $n=370)$

Trong 8 loại vắc xin cần tiêm cho trẻ dưới 1 tuổi, kết quả nghiển cứu cho thấy có 351 tỷ lệ tiêm chủng đều thấp hơn $95 \%$ so với mục tiêu của Bộ Y tế. Tỷ lệ trẻ được tiêm đúng lịch theo từng loại vắc xin cũng rất thấp. Trong đó, IPV có tỷ lệ tiêm đúng lịch thấp nhất $15.1 \%$, cao nhất là DPT-VGBHib mũi 1 có tỷ lệ tiêm đúng lịch là $51.9 \%$ trong 370 trẻ tham gia nghiên cứu.

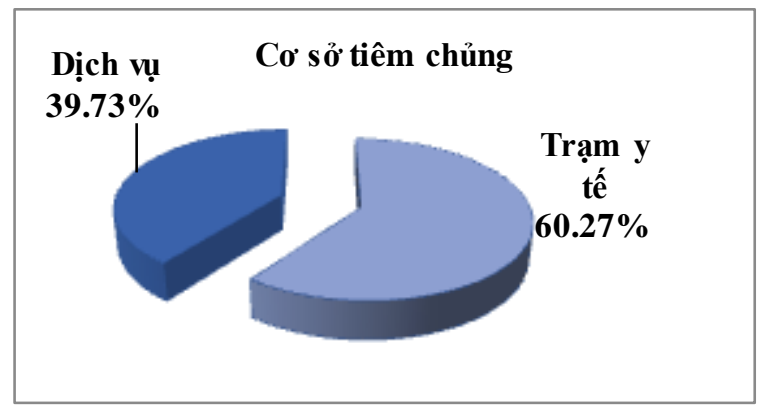

Biểu đồ 3.2. Cơ sở tiêm chủng các loại vắc xin cho trẻ dưới 1 tuôi $(n=370)$

Bà mẹ/người chăm sóc trẻ chọn tiêm chủng ở cơ sở tiêm chủng miễn phí là trạm y tế (223 đối tượng), chiếm tỷ lệ $60.27 \%$ cao hơn nhóm bà mẹ/người chăm sóc trẻ chọn tiêm chủng có thu phí ở các cơ sở tiêm chủng dịch vụ (39.75\%).

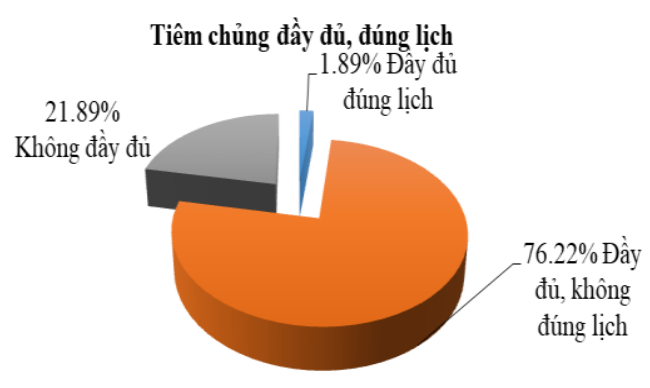

Biểu đồ 3.3. Tiêm chủng đầy đủ, đúng lịch cả 8 loại vắc xin $(n=370)$

Trong 370 trẻ tham gia nghiên cứu, có $78.11 \%$ trẻ được tiêm chủng đầy đủ 8 loại vắc xin trong chương trình tiêm chủng mở rộng cho trẻ dưới 1 tuổi. Trong đó, tỷ lệ tiêm chủng đầy đủ đúng lịch là $1.89 \%$, đây đủ không đúng lịch là $76.22 \%$.

Mối liên quan đến tỷ lệ tiêm chủng đây đủ của trẻ

Bảng 1. Mối liên quan giữa đặc tính me đến tỷ lệ TCĐĐ của trẻ $(n=370)$

\begin{tabular}{|c|c|c|c|c|c|c|}
\hline \multirow[b]{2}{*}{ Đặc tính } & \multicolumn{2}{|c|}{ Đầy đủ } & \multicolumn{2}{|c|}{ Không đây đủ } & \multirow[b]{2}{*}{$\mathbf{p}$} & \multirow[b]{2}{*}{ PR (95\%CI) } \\
\hline & $\begin{array}{c}\text { Tânsố } \\
(\mathbf{n}=\mathbf{2 8 9})\end{array}$ & $\begin{array}{l}\text { Tỷ lệ } \\
(\%)\end{array}$ & $\begin{array}{c}\text { Tân số } \\
(\mathrm{n}=\mathbf{8 1})\end{array}$ & $\begin{array}{l}\text { Tỷ lệ } \\
(\%)\end{array}$ & & \\
\hline Trình độ học vấn & 47 & 65.28 & & & & \\
\hline
\end{tabular}




\begin{tabular}{|c|c|c|c|c|c|c|}
\hline Dưới - hễt cấp 1 & 65 & 80.25 & 25 & 34.72 & & 1 \\
Học hết cấp 2 & 88 & 83.02 & 16 & 19.75 & 0.04 & $1.23(1.01-1.50)$ \\
Học hết cấp 3 & 89 & 80.18 & 18 & 16.98 & 0.01 & $1.27(1.05-1.54)$ \\
Trên cấp 3 & & & 22 & 19.82 & 0.04 & $1.23(1.01-1.49)$ \\
\hline Nơi ở hiện tại: Thành thị & 185 & 73.41 & 66 & 26.59 & & 1 \\
Vùng ven & 74 & 90.24 & 8 & 9.76 & 0.00 & $1.23(1.11-1.36)$ \\
Nông thôn & 30 & 83.33 & 6 & 16.67 & 0.12 & $1.14(0.96-1.34)$ \\
\hline
\end{tabular}

Có mối liên quan giữa trình độ học vấn, nơi ở hiện tại của me/người chăm sóc trẻ tới tỷ lệ tiêm chủng đầy đủ các loại vắc xin cho trẻ dưới 1 tuổi. Sự khác biệt này có ý nghĩa thống kê với $\mathrm{p}$ mỗi nhóm đều $<0.05$

Bảng 2. Mối liên quan giữa sức khỏe của trẻ với tỷ lệ TCĐĐ của trẻ $(n=370)$

\begin{tabular}{|c|c|c|c|c|c|c|}
\hline \multirow[b]{2}{*}{ Đăcc tính } & \multicolumn{2}{|c|}{ Đây đủ } & \multicolumn{2}{|c|}{ Không đây đủ } & \multirow[b]{2}{*}{$\mathbf{0}$} & \multirow[b]{2}{*}{ PR (95\%CI) } \\
\hline & $\begin{array}{c}\text { Tân số } \\
(n=289)\end{array}$ & $\begin{array}{l}\text { Tỷ lệ } \\
(\%)\end{array}$ & $\begin{array}{c}\text { Tân số } \\
(n=81)\end{array}$ & $\begin{array}{l}\text { Tỷ lệ } \\
(\%)\end{array}$ & & \\
\hline $\begin{array}{c}\text { Số tiêm chủng: Không } \\
\text { Có }\end{array}$ & $\begin{array}{c}2 \\
287\end{array}$ & $\begin{array}{l}19.83 \\
80.17\end{array}$ & $\begin{array}{l}10 \\
71\end{array}$ & $\begin{array}{l}83.33 \\
36.31\end{array}$ & 0.00 & $\begin{array}{c}1 \\
4.81(1.36-17.06)\end{array}$ \\
\hline
\end{tabular}

Trẻ có số tiêm chủng có tỷ lệ tiêm chủng đầy đủ 8 loại vắc xin trong chương trình TCMR cao hơn gấp 4.81 lần so với trẻ không có sổ tiêm chủng. Sự khác biệt này có y nghĩa thống kê $(p=0.00)$ KTC 95\% (1.36-17.06).

Bảng 3. Mối liên quan giữa một số yếu tố và tỷ lệ TCĐĐ của trẻ (n-370)

\begin{tabular}{|c|c|c|c|c|c|c|}
\hline \multirow[b]{2}{*}{ Thiếu thông tin } & \multicolumn{2}{|c|}{ Đây đủ } & \multicolumn{2}{|c|}{ Không đâyy đủ } & \multirow[b]{2}{*}{$\mathbf{p}$} & \multirow{2}{*}{$\begin{array}{l}\text { PR } \\
\text { (KTC } \\
95 \%)\end{array}$} \\
\hline & $\begin{array}{l}\text { Tân số } \\
\text { (n 289) }\end{array}$ & $\begin{array}{l}\text { Tỷ lề } \\
(\%)\end{array}$ & $\begin{array}{l}\text { Tân số } \\
\text { (n 81) }\end{array}$ & $\begin{array}{l}\text { Tỷ lệ } \\
(\%)\end{array}$ & & \\
\hline $\begin{array}{r}\text { Biết nơi tiêm, giờ tiêm: Có } \\
\text { Không }\end{array}$ & $\begin{array}{c}285 \\
4\end{array}$ & $\begin{array}{l}79.61 \\
33.33 \\
\end{array}$ & $\begin{array}{c}73 \\
8\end{array}$ & $\begin{array}{l}20.39 \\
66.67\end{array}$ & 0.00 & $\begin{array}{c}2.38 \\
(1.07-5.32)\end{array}$ \\
\hline $\begin{array}{c}\text { Trẻ hoãn tiêm, không tiêm lại } \\
\text { Có } \\
\text { Không }\end{array}$ & $\begin{array}{c}60 \\
229\end{array}$ & $\begin{array}{l}68.18 \\
81.21\end{array}$ & $\begin{array}{l}28 \\
53\end{array}$ & $\begin{array}{l}31.82 \\
18.79\end{array}$ & 0.01 & $\begin{array}{l}0.84(0.72- \\
0.98)\end{array}$ \\
\hline $\begin{array}{c}\text { Không tin vào TC ngừa bệnh } \\
\text { Có } \\
\text { Không }\end{array}$ & $\begin{array}{c}49 \\
232\end{array}$ & $\begin{array}{l}67.12 \\
80.81\end{array}$ & $\begin{array}{l}26 \\
57\end{array}$ & $\begin{array}{l}32.82 \\
19.19\end{array}$ & 0.01 & $\begin{array}{c}0.83 \\
(0.7-0.98)\end{array}$ \\
\hline $\begin{array}{c}\text { Nghe đồn không đúng về TC } \\
\text { Có } \\
\text { Không }\end{array}$ & $\begin{array}{l}27 \\
263\end{array}$ & $\begin{array}{l}61.36 \\
80.37\end{array}$ & $\begin{array}{l}17 \\
64\end{array}$ & $\begin{array}{l}38.64 \\
19.63\end{array}$ & 0.00 & $\begin{array}{c}0.76 \\
(0.60-0.97)\end{array}$ \\
\hline $\begin{array}{c}\text { Không có/hết văc xin: Có } \\
\text { Không }\end{array}$ & $\begin{array}{c}41 \\
248\end{array}$ & $\begin{array}{l}65.08 \\
80.78\end{array}$ & $\begin{array}{l}22 \\
59\end{array}$ & $\begin{array}{l}60.32 \\
19.22\end{array}$ & 0.01 & $\begin{array}{c}0.81 \\
(0.67-0.97)\end{array}$ \\
\hline $\begin{array}{c}\text { Mẹ bận không đỉ TC: Có } \\
\text { Không }\end{array}$ & $\begin{array}{c}37 \\
252\end{array}$ & $\begin{array}{l}62.71 \\
18.97 \\
\end{array}$ & $\begin{array}{l}22 \\
59\end{array}$ & $\begin{array}{l}37.29 \\
81.03\end{array}$ & 0.00 & $\begin{array}{c}0.77 \\
(0.63-0.95)\end{array}$ \\
\hline $\begin{array}{c}\text { Trẻ đang bị bệnh: Có } \\
\text { Không }\end{array}$ & $\begin{array}{l}155 \\
134\end{array}$ & $\begin{array}{l}72.77 \\
85.35\end{array}$ & $\begin{array}{l}56 \\
23\end{array}$ & $\begin{array}{l}27.23 \\
14.43\end{array}$ & 0.00 & $\begin{array}{c}0.85 \\
(0.77-0.95)\end{array}$ \\
\hline
\end{tabular}

Mẹ biết về thời gian tiêm, nơi tiêm có liên quan đến có mối liên quan đển tỳ lệ tiêm chủng đây đủ 8 loại vắc xin cho trẻ dưới 1 tuổi trong chương trình TCMR $(p=0.00)$, (KTC 95\%1.07-5.32).

Bảng 4. Mối liên quan giữa nơi tiêm chủng và tỷ lệ TCĐĐ của trẻ $(n=370)$

\begin{tabular}{|c|c|c|c|c|c|c|}
\hline \multirow[b]{2}{*}{ Cớ sở tiêm chủng } & \multicolumn{2}{|c|}{ Đầy đủ } & \multicolumn{2}{|c|}{ Không đâyy đủ } & \multirow[b]{2}{*}{$\mathbf{p}$} & \multirow[b]{2}{*}{ PR (95\%CI) } \\
\hline & $\begin{array}{c}\text { Tânsố } \\
(\mathrm{n}=289)\end{array}$ & $\begin{array}{l}\text { Tỷ lệ } \\
(\%)\end{array}$ & $\begin{array}{c}\text { Tân số } \\
(\mathrm{n}=81)\end{array}$ & $\begin{array}{l}\text { Tỷ lệ } \\
(\%)\end{array}$ & & \\
\hline $\begin{array}{l}\text { Dịch vự } \\
\text { Trạm y tế }\end{array}$ & $\begin{array}{c}66 \\
223\end{array}$ & $\begin{array}{c}44.90 \\
100.00 \\
\end{array}$ & $\begin{array}{c}81 \\
0 \\
\end{array}$ & $\begin{array}{l}55.10 \\
0.00\end{array}$ & 0.00 & $\begin{array}{c}2.23 \\
(1.86-2.66) \\
\end{array}$ \\
\hline
\end{tabular}

Có mối liên quan giữa lựa chọn cơ sở tiêm chủng với tỷ lệ tiêm chủng đầy đủ Tỷ lệ tiêm chủng đây đủ 8 loại vắc xin cho trẻ dưới 1 tuổi khi bà me chọn cơ sở tiêm là trạm y tế cao hớn so với bà me chọn cớ sở tiêm dịch vụ là 2.23 lần (KTC 95\% (1.86-2.66). Sự khác biệt này có ý nghĩa thống kê với $(p=0.00)$.

\section{BÀN LUÂN}

Theo UNICEF, WHO và Liên minh toàn cầu về vắc xin và tiêm chủng (GAVI) cho biết tỷ lệ tiêm vắc xin phòng bệnh cho trẻ em trên toàn câu đã có sự sut giảm đáng báo động. Có nhiều nguyên nhân dấn đến tình trạng này. Trước tình hình đó, 
chúng tôi tiến hành khảo sát trên 370 đối tươnng là bà me trên địa bàn thành phố Phan Thiết,tỉnh Bình Thuận đã ghi nhận được những nội dung sau:

4.1. Đặc điểm tỷ lệ tiêm chủng đây đủ, đúng lịch. Trong 370 trẻ tham gia nghiên cứu có 351 trẻ tiêm ngừa BCG chiếm tỷ lệ cao nhất $94.4 \%$, kế đến là mũi DPT-VGB-Hib mũi 1 và OPV1 có tỷ lệ là $94.6 \%$ và $91.4 \%$. Tỷ lệ trẻ được tiêm mũi IPV thấp, với $84.3 \%$. Bên cạnh đó, tỷ lệ trẻ được tiêm đúng lịch theo từng loại vắc xin cũng rất thấp. Trong đó, IPV có tỷ lệ tiêm đúng lịch thấp nhất $15.1 \%$, cao nhất là DPT-VGB-Hib mũi 1 có tỷ lệ tiêm đúng lịch là $51.9 \%$ trong 370 trẻ tham gia nghiên cứu. Hầu hết các kết quả này đều thấp hơn so với nghiên cứu khác[2]. Tuy nhiên,kết quả này laai cao hơn so với một số nghiên cứu như nghiên cứu của tác giả Yihunie Lakew và cộng sựvới mục tiêu là xác đinh tỷ lệ TC đầy đủ ở trẻ 12 đến 23 tháng và một số các yếu tố ảnh hưởng đến tỷ lệ TC của một nghiên cứu tại Ethiopia.

Có $78.11 \%$ trẻ được tiêm chủng đầy đủ 8 loại vắc xin trong chương trình tiêm chủng mở rộng cho trẻ dưới 1 tuổi. Tỷ lệ này thấp hơn với tỷ lệ tiêm chủng toàn quốc năm 2020 là 95\% [8]. Kết quả nghiên cứu của chúng tôi cũng thấp hơn nghiên cứu cua tác giả Hoàng Anh Thắng [6]. Kết quả có thể là do kết quả nghiên cứu của chúng tôi do nghiên cứu tỳ lệ tiêm chủng vào thời điểm xảy ra đại dich COVID-19 đang khiến các hệ thống y tế căng mình ứng phó và gây gián đoạn chương trình tiêm chủng ở nhiều nơi [8]. Tuy nhiên kêt quả này cũng còn cao hơn so với một số nghiên cứu tại những địa phương khác như nghiên cứu của tác giả Phí Thị Hương Liên thị thành phố Hà Nội, năm 2016 (70.82\%) [4].

Tỷ lệ tiêm chủng đầy đủ và đúng lịch của trẻ sẽ phản ánh được cơ thể có đủ khả năng để đáp ứng nhanh khi tiếp xúc với tác nhân gây bệnh.Tỷ lệ trẻ được tiêm chủng đây đủ và đúng lịch 8 loại vắc xin trong chương trình tiêm chủng mở rộng cho trẻ dưới 1 tuổi chiếm tỷ lệ rất thấp, 1.98\%. Kết quả này thấp hơn nghiên cứu của tác giả Lý Thị Thúy Vân và cộng sự về trong nghiên cứu về thực trạng tiêm chủng đầy đủ đúng lịch ở trẻ dưới 1 tuổi thực hiện năm 2020 (4,3\%)[8].

4.2. Mối liên quan đến tỷ lệ tiêm chủng đây đủ, đúng lịch. Có mối liên quan giữ nơi ở hiện tại và tỷ lệ tiêm chủng đầy đủ 8 loại vắc xin cho trẻ dưới 1 tuổi trong chương trình TCMR. Kết quả này khác với nghiên cứu của tác giả Hoàng Anh Thắng tại Vũng tàu năm 2020[6], tác giả Đố Thị Thắm tại Yên Bái[5].

Nghiên cứu đã xác định được mối liên quan giữ trình độ học vấn của mẹ với tỷ lệ tiêm chủng đúng lịch 8 loại vắc xin cho trẻ dưới 1 tuổi trong chương trình TCMR. Me có trình độ học vấn dưới 1 ít được tiếp cận nhiều nguồn thông tin chính xác và không hiểu rõ tầm quan trọng của việc tiêm chủng phòng bệnh cho con không chủ động tiêm chủng cho con. Kết quả này cho thấy tương đồng với kết quả của tác giả Hoàng Anh Thắng. cần tập chung truyền thông, hướng dãn nhóm bà mẹ có trình độ học vấn thấp, đặc biệt là nhóm bà me có trình độ học vấn từ cấp 1 trở xuống hãy đưa trẻ đi tiêm chủng đầy đủ, đúng lịch các loại vắc xin trong chương trình Tiêm chủng mở rộng tại các Trạm Y tế xã, phường, thị trấn và cả những vắc xin chưa có trong chương trình Tiêm chủng mở

Nghiên cứu xác định được mối liên quan giữ trẻ có sổ tiêm chủng Sổ tiêm chủng được cấp phát cho để bố mẹ và nhân viên y tế tiện theo dõi quá trình tiêm chủng của trẻ. Kết quả này tương đồng với kết quả của tác giả Đố Thị Thắm tại Yên Bái [5].

Kết quả nghiên cứu cho thấy: Yếu tố mẹ không đưa trẻ đi tiêm lại khi bị hoãn tiêm, thời gian tiêm, nơi tiêm; không tin tưởng vào tiêm chủng; hết vắc xin; mẹ bận việc lựa chọn cơ sở tiêm chủng có liên quan đến tỷ lệ tiêm chủng đầy đủ của trẻ.

\section{KẾT LUẬN}

Tỷ lệ tiêm chủng đây đủ, 8 loại vắc xin truong chương trình tiêm chủng mở rộng là $78.11 \%$, tiêm chủng đúng lịch là $1.98 \%$. Các yếu tố ảnh hưởng đến tỷ lệ tiêm chủng đây đủ 8 loại vắc xin cho trẻ dưới 1 tuổi bao gồm: trình độ học vấn, nơi ở, sổ tiêm chủng, lựa chọn nơi tiêm, các yếu tố về thiếu thông tin tiêm chủng, trở ngại tiêm chủng, thiếu vận động về tiêm chủng.Có kế hoạch nâng cấp, cải tiến về cơ sở vật chất và các hình thức đáp ứng dịch vụ chăm sóc trẻ tại các trạm $Y$ tế, dự trữ vắc xin quốc gia để có thể huy động và thu hút cộng đồng chủ động đưa trẻ ra tiềm chủng đầy đủ, đúng lịch.

\section{TÀI LIÊU THAM KHẢO}

1. Bộ Y tế (2016) Báo cáo tổng kết tiêm chủng mở rộng 2016, trg: 3-4.

2. Trân Thị Thúy Hà, Lê Hải Đăng, Đào Hữu Thân1, Ngố Khánh Hoàng, Hoàng Thi Kim Oanh, Lê Thị Thảo1, et al. (2020) "Tỷ lệ tiêm chủng đầy đủ, đúng lịch các vắc xin của trẻ dưới 1 tuổi tại huyện Thanh Trì, thành phố Hà Nội năm 2019". Tạp chí Y học dự Phòng, 30 (7), tr.59 .

3. Đăng Cao Khoa, Nguyễn Thị Hường (2019) "Tình hình tiêm chủng đung lịch của trẻ em dưới 2 tuổi và một số yếu tố liên quan tai phường Hương Long, thành phố Huế, năm 2017". Tạp chí y học 
dự phòng, Tập 29 (số 5), trg: 107.

4. Nguyễn Nhật Cảm, Phí Thị Hương Liên (2017) "Thức trang tiêm chủng đầy đủ đúng lich 8 loai vắc xin ở trẻ em dưới 1 tuổi và yếu tố liên quan tại khu vực thành thị thành phố Hà Nội, năm 2016". Tạp chí y học dự phòng, Tập 27 ( số 6), trg: 118.

5. Đổ Thị Thắm (2018) "Thực trang tiêm chủng đây đủ, đủng lich và một số yếu tố ảnh hưởng ở tré dưới 1 tuổi tại huyện Trạm Tấu, Mù Cang Chải, tỉnh Yên Bái năm 2017". Tap chí y hoc dư phòng, diên đàn khoa học của hội y học dự phòng, 28 (4), 9.

6. Hoàng Anh Thẳng (2020) "Tỷ lệ tiêm chủng đây đủ, đúng lịch của tré em giai đoạn 5 năm (2015-
2019) và một số yếu tố liên quan đến tỷ lệ tiêm chủng đầy đủ, đúng lịch tại Thành Phố Vũng Tàu, tỉnh Bà Ria Vũng Tàu". Khóa luân tốt nghiêp Thac sỹ Y học dự Phòng 2020 - Đại học Y Dược tp Hồ Chí Minh,

7. UNICEP Chương trình Tiêm chủng https://www.unicef.org/vietnam/vi/ti\%C3\%AAmch\%E1\%BB\%A7ng,

8. Lý Thị Thúy Vân, Đỗ Thi Thanh Toàn, Dương Thị Hồng, Nguyễn Công Luật, Nguyê̂n Bá Đoàn, Nguyến Mai Khanh, et ăl. (2020) "Thức trạng tiêm chủng đây đủ đúng lịch cho trẻ dưới 1 tuổi tại huyênn Bình Liễu, tỉnh Quảng Ninh năm 2020". Tạp chí Y học Dự phòng, 30 (7), 35.

\title{
KẾT QUẢ ĐIỀU TRI HÓA XẠ TRI UNG THƯ TRỰC TRÀNG GIAI ĐOÂN III TRƯớC MỔ
}

\author{
Hoàng Văn An*, Hoàng Mạnh An*, Nguyễn Anh Tuấn**
}

TÓM TẮT

Mục tiêu: Đánh giá kết quả điều trị hóa xạ trị ung thư trực tràng giai đoạn III với Cappecitabine trước mổtại Bệnh viện Trung ương quân đội 108. Đối tượng và phường pháp: Nghiên cứu mồ tả tiến cứu và hồi cứu từ tháng 12.2015 đến tháng 3.2020 trên 73 bệnh nhân ung thư trực tràng giai đoạn IIIcòn khả năng phẫu thuật, được hóa xạ tiền phẫu liều $50,4 \mathrm{~Gy} / 28 \mathrm{fx}$ trong 5,5 tuần cùng với Capecitabine $825 \mathrm{mg} / \mathrm{m} 2$, 2 lần/ngày, x 5-7 ngày/tuần. Các bệnh nhân được tiến hành phẫu thuật sau 4-12 tuần kết thúc hóa xạ trị. Đánh giá độc tính do hóa xạ trị, đáp ứng trên lâm sàng, đáp ứng trên giải phẫu bênh sau mổ, khả năng bảo tồn cơ thắt hậu môn và biến chứng sau mổ. Kết quả: Tỷ lệ đáp ứng toàn bộ trên lâm sàng là $75,3 \%(55 / 73)$, trong đó có $8,2 \%(6 / 73)$ đáp ứng hoàn toàn. Trên giải phẫu bệnh sau mổ, tỷ lệ bệnh nhân đáp ứng làm giảm giai đoạn khối u $(\mathrm{T})$ là $54,79 \%$ (40/73), trong đó 4,1\% (3/73) đạt đáp ứng hoàn toàn (pTO). Tất cả bệnh nhân dung nạp điêuu trị tốt, không có độc tính độ 4, thường gặp viêm trực tràng do xạ trị độ $1-2$ chiếm $27,4 \%$ (20/73) và độ 3 có 01 trường hợp chiếm $1,3 \%$, viêm da do xa trị đồ $1-2$ có30,1\% (22/73), mệt mỏi độ $1-2$ có $17,8 \%$ (13/73), viêm đường tiết niệu đô 1 có $8,2 \%(6 / 73)$, sút cân $9,6 \%$ (7/73). Phẫu thuật bảo tồn cơ thắt đạt $84,9 \%$ (62/73). Biến chứng sau mổ chỉ có $6,8 \%(5 / 73)$ rò miệng nối. Kết luận: Điều trị hóa xa trị ung thư trực tràng giai đoạn III với Capecitabine đạt tỷ lệ cao giảm giai đoạn sau điều trị, làm tăng khả năng phẫu thuật bảo tồn cơ thắt.

Tư khóa: Hóa xạ tiền phẫu, ung thư trực tràng.

*Bệnh viện Quân y 103

**Bênh viên TƯQQ 108

Chịu trách nhiệm chính: Hoàng Văn An

Email: hoangnguyenantam@gmail.com

Ngày nhận bài: 17/10/2021

Ngày phản biên khoa hoc: 19/11/2021

Ngày duyệt bài: 12/12/2021

\section{SUMMARY \\ THE RESULTS OF PREOPERATIVE CHEMO- RADIOTHERAPY TREATMENT FOR STAGE III RECTAL CANCER}

Objectives: To evaluate the results of surgery treatment for stage III rectal cancer with preoperative chemo-radiotherapy with Cappecitabine at Central Military Hospital 108. Subjects and methods: Progressive and retrospective descriptive research on 73 patients with rectal cancer Stage III from December 2015 to March 2019 who have received preoperative chemoradiotherapy with $50.4 \mathrm{~Gy} / \mathrm{Fx}$ dose in 5.5 weeks with Capecitabine $825 \mathrm{mg} / \mathrm{m2}$, twice a day $x$ 5-7 days/week and surgery. All of the patients underwent surgery after 4 to 12 weeks since finishing chemoradiotherapy. Evaluate the toxicity of chemoradiotherapy, clinical response, postoperative pathological anatomy response, sphincter preservation and postoperative complications. Results: Rate of clinical complete response is $75,3 \%(55 / 73)$, including $8.2 \%(6 / 73)$ of comprehensive response. In terms of postoperative anatomy, rate of patients with tumor $(T)$ period reduction response is $54.79 \%$ (40/73), including $4.1 \%(3 / 73)$ of comprehensive response (pT0). All patients tolerated treatment well, no toxicity at level 4 . Rectal inflammation caused by radiation at level 1-2 accounts for $27.4 \%(20 / 73)$ and at level 3 accounts for $1.3 \%$ with 1 case, dermatitis due to radiation at level $1-2$ accounts for $30.1 \%(22 / 73)$, fatigue at level $1-2$ accounts for $17.8 \%$ (13/73), urinary tract inflammation at level 1 accounts for $8.2 \%$ (6/73), weight loss accounts for $9.6 \%$ (7/73). Anal sphincter conservation surgery reaches $84.9 \%$ (62/73). Postoperative complications account for only $6.8 \%(5 / 73)$ of leakage. Conclusion: Stage III rectal cancer treatment results by preoperative chemoradiotherapy with Capecitabine have achieved high rate of post-operative period reduction and increase the capability of anal sphincter conservation surgery.

Key words: Preoperative chemo-radiotherapy, rectal cancer. 